The interplay between models and experimentation is discussed and the need for improved data on the mass output of an avalanche, of its detailed velocity history, and of the force on large objects is emphasized. Methods being used to try to supply this information are discussed; gamma-ray measurements for specific mass, high-speed stereophotogrammetry for velocity, and various pressure sensors for the force. The possibility of releasing real powder avalanches to enable such measurements to be made more reliably is being investigated.

\title{
FINITE-ELEMENT ANALYSIS OF SNOW ON SLOPES
}

\author{
By J. P. NAVARre \\ (Centre d'Études de la Neige, Domaine Universitaire, 38402 Saint-Martin-d'Hères, France) \\ and J. Desrues \\ (Laboratoire de Mécanique des Sols, Domaine Universitaire, 38402 Saint-Martin-d'Hères, \\ France)
}

Abstract. This study describes the application of an incremental rheological law for snow in a finite-element model. The computation simulates the variation of strains and stresses in a layer of snow covering an inclined plane of variable slope. At the same time, a physical simulation was carried out in a cold room to verify the results obtained with the model. This work illustrates the value of a finite-element model for snow, but also the complications attendant on its use. Indeed, the integration of the law may lead to oscillations due to the rate of variation of the stresses, and this means that the time increment must be modulated during the computation.

\section{RADAR FOR AVALANCHES-MEASUREMENT AND WARNING}

\author{
By W. Fritzsche \\ (Institut für Elektronik, Technische Universität Graz, Inffeldgasse 12, A-8010 Graz, Austria)
}

Abstract. Automatic measuring devices can greatly facilitate the difficult task of persons responsible for avalanche warnings or the closing of roads or ski runs. In favourable cases the traffic can be directly stopped by means of radar when an avalanche is released. The development of the necessary bases and technical realization are important tasks of research. Above all the snow height or the mass of snow (from a snow gauge) or the onset of movement of an avalanche need to be measured automatically. For research it is also interesting to determine the speed of the avalanche and its distribution in given coordinates-along and across the avalanche track. With automatic snow gauges two operating methods have proved successful: (1) ultrasonic sounding from a point above the snow; (2) absorption of cosmic radiation; apparatus for detecting this can also be built into the soil of a slope in the avalanche release zone. The moment of avalanche release can be identified by means of radar in the X-band with moving-target indicator and micro-computer evaluation. 